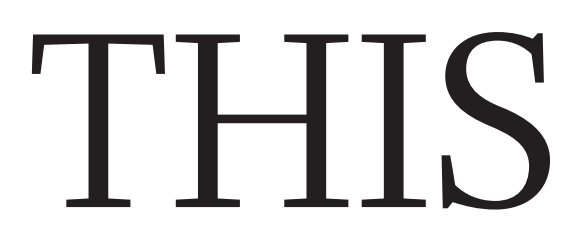

EDITORIALS
CLIMATE Pause in global warming pushes science onwards $\mathbf{p . 6}$

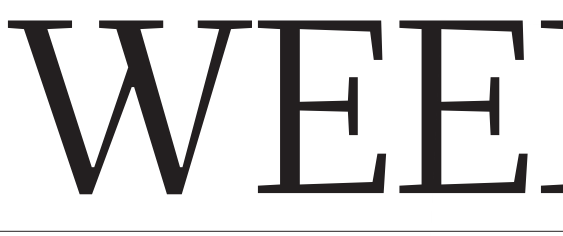

WORLD VIEW Early-career researchers should not wait to make a difference $\mathbf{p . 7}$
SUGAR MICE Implanted human cells use light to turn on insulin $\mathbf{p . 9}$

\title{
Empty-chair syndrome
}

\author{
As US President Donald Trump registers 100 days in office, the chaos of his administration is \\ marked by a failure to make key appointments.
}

$\mathrm{F}$ or more than 80 years, the US media and political scholars have gauged a new president's potential on the basis of his administration's performance in its first 100 days. The time-honoured — if increasingly tiresome - tradition began when Franklin Delano Roosevelt took office in 1933. He was able to act fast, being blessed with a Congress controlled by his own political party. And he needed to do so, his presidency being cursed with the Great Depression, a financial emergency that demanded quick and decisive action.

The 100-days benchmark is by its nature arbitrary, and projections based on it can be superficial. Many historic presidential achievements - such as Barack Obama's reform of the US health-care system - happened in the subsequent days (all 1,361 of them) of a typical four-year term.

But the first few months of an administration are crucial to filling staff vacancies. The White House Transition Project (WHTP), a nonpartisan effort to ease the transfer of power by providing information to the new administration's staff, has found that posts take longer to fill as time drags on: the longer a president waits to nominate candidates, the slower the US Senate is to confirm them.

When Trump passed the 100-day mark this weekend, he became the slowest president to stock an administration in four decades, the WHTP says. He has yet to nominate candidates for hundreds of empty seats - some of them vitally important to the country's science policy and research direction.

On 12 April, Republicans in Congress wrote to Trump to urge him to fill two vacancies on the Nuclear Regulatory Commission, an independent panel that oversees civilian use of radioactive materials in power plants and other applications. Without those appointments, the commission will not have the number of people mandated by law for it to make decisions when its chair's term ends on 1 July. The Federal Energy Regulatory Commission fell below that level in February.

Trump has blamed some delays on the Senate, which must confirm nearly 1,000 of his appointments. But he has also suggested that his inaction is a deliberate strategy to pare down the size of government. "What do all of these people do?" he said in one interview. "You don't need all those jobs."

The United States certainly needs some of them. Whether owing to impairment, intention or inexperience, Trump's dithering over key scientific positions puts the country's research community and the broader public at risk.

For many researchers, the main concern has been the lack of a science adviser to head the Office of Science and Technology Policy. The absence of a voice for science in the administration may have contributed to the draconian cuts to the US National Institutes of Health and Environmental Protection Agency proposed in Trump's 2018 budget blueprint. (The proposal didn't mention the National Science Foundation at all.) A science adviser could also have informed the administration of the damaging consequences for science of proposed immigration policies. And he or she could offer counsel when scientific crises - the next Zika virus or oil spill, for example - arise. And arise they will.

Biomedical researchers, meanwhile, are waiting to see how long Francis Collins will continue to serve as director of the US National Institutes of Health. The National Cancer Institute, the head of which is also appointed by the president, has been led by its deputy direc-
"Trump's dithering puts the country's research community and the broader public at risk." require a coordinated response across agencies.

In 1933, Roosevelt passed 76 laws in his first 100 days as he laboured to reshape the nation's economy. He set a high bar for efficiency: no president has measured up to his achievement since. (Eight years into his presidency, Roosevelt appointed the nation's first science adviser, engineer Vannevar Bush.)

With any new president comes uncertainty, and no administration completes its full roster of appointments by the end of its first year. But Trump is lagging well behind his predecessors, and is fostering a damaging sense of uncertainty by suggesting that he will leave these chairs empty.

\section{Integrity and PIs}

\section{Funders should force universities to support the research health of their research groups.}

$\mathrm{L}$ ast month, the US National Academies of Sciences, Engineering, and Medicine published a report called Fostering Integrity in Research. Later this month, the 5th World Conference on Research Integrity will be held in Amsterdam. Over the years, universities have followed some funders' mandates to improve the prevention and investigation of misconduct. Many discussions have been held about unreliable research.

None of these initiatives pays sufficient attention to a specific issue: the research health of research groups and the people who lead them. This includes technical robustness of lab practices, assurance of ethical integrity and the psychological health and well-being of group members. 
Principal investigators (PIs), the linchpins of the scientific process and of integrity, are under ever-increasing pressures from many sources.

The cultures of departments and institutions may be influential. Last month's report draws attention to survey-based tools that can assess the health of an organization's research culture (such as that at go.nature. $\mathrm{com} / 2 \mathrm{p} 3$ fjed). But it would be more to the point to assess the health of research groups, which has much greater influence on trainees.

For example, how, if at all, are group members' data scrutinized by other members or the PI, perhaps by spot-checking? To what extent does a PI ensure that a graduate student or postdoc with a strong research claim is not deceiving themselves? In 2008, a study of case files concerning trainees found guilty of misconduct concluded that nearly three-quarters of the trainees' mentors had not directly reviewed source data (D. E. Wright et al. Sci. Eng. Ethics 14, 323-336; 2008). What bandwidth does the PI have for such oversight?

Then there is a PI's approach to other essential aspects of research. For example, do group members get experience of peer review and grant applications? Is such training neglected, or are trainees so burdened with it that their own research is compromised?

And in relation to psychological well-being, to what extent do group members perceive themselves to be treated fairly, in good times or bad? At least three organizations - Future of Research, Rescuing Biomedical Research and the Global Young Academy — have sprung up in the past decade to advocate for early-career researchers, suggesting that trainees do not feel they are receiving just treatment. In 2013, an anonymous survey at one institution found that almost one-third of trainees felt pressure to back a mentor's research hypothesis even when data did not support it, and that nearly half knew of mentors who required trainees to have a high-impact publication before leaving the

lab (A. Mobley et al. PLoS ONE 8, e63221; 2013).

What of the broader needs of the PI? Does the institution provide support for ongoing data management or training in group organization and leadership? Probably not much - a 2014 survey of around 3,500 faculty members funded by the US National Institutes of Health (NIH) found that only around one-quarter had had opportunities to receive training in being a better mentor (S. L. Titus and J. M. Ballou

"Institutions should help PIs assess their groups and allow independent checks."
Sci. Eng. Ethics 20, 221-235; 2014).

Institutions should pursue such support and oversight, to help PIs assess their groups and to allow independent checks. And funders should insist on such support and appraisals. After all, what isn't measured tends to get ignored.

Sometimes, funders' efforts can undermine this process. To its great credit, the NIH has pursued measures requiring researchers to increase the reproducibility of their work. But it has not put enough money behind them, apparently believing that researchers should do the extra work anyway. Few other national funders have introduced any measures or financial support to enhance the technical and ethical integrity of research groups.

The National Academies report provides a helpful framework for such support to reduce what it refers to as "detrimental research practices". And assisting PIs will produce benefits that accrue over generations. But it will take resources to make the system rise to expectations of objectivity, openness and good leadership, and no one seems willing to bite the bullet and move the funds - even though that would underpin public faith in science. Support for PIs in sustaining healthy research groups is thus a crucial target for investment.

\section{What pause?}

\section{The apparent slowdown in global warming has been shown up for what it was - overcooked.}

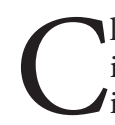

limate-science denial is quick to recognize opportunity. And its action follows a predictable, two-stage pattern. Step one: invent a false narrative claiming that the mainstream scientific community expects climate change to proceed as an uninterrupted, ineluctable process. Step two: pounce on any divergence from said narrative as evidence that said understanding of climate science is flawed.

The approach, while intellectually vacuous, can have the perverse outcome of leading to real progress - and to science that might not have been done otherwise. One such case is the claimed (and now definitely ended) global-warming 'hiatus', more properly called 'the most recent instance of normal climate variability'.

Some background: the El Niño weather event in 1997 and 1998 belched a great bolus of heat from the ocean into the atmosphere, a release that was entirely consistent with expectations - as was the heady spike in global mean surface temperature that followed.

From the top of the Himalayas, the rest of Earth is downhill. And, in a similar way, the 1998 peak in temperature offered an easily visualized time that climate sceptics could cherry-pick as a starting point for a 'hiatus', 'pause' or 'slowdown' in climate change. It's true (of course) that the next few years saw a reduced rate of warming, or maybe even a slight cooling. And it's also true that, soon after, some analyses showed that these observations were beginning to diverge from the suite of projections made by climate models.

A few responses emerged. First: yawn — "This is nothing more than the sort of normal variability one should expect in the climate system, and models should not be expected to predict any specific dip or peak." Second: hysteria - "Climate scientists have no idea what controls the climate system." Third: interesting — "Let's figure this out." Happily, most of the climate-science community adopted the third option. The result was a flood of publications on the topic, and the only half-joking suggestion that Nature's publisher should launch a new journal called Nature Hiatus.

As discussed this week in an Analysis article (page 41) - and in an accompanying News \& Views (page 37) - much controversy surrounding the hiatus could have been avoided if researchers had used more-careful definitions and terminology. But after a full scientific shake-out, what emerges? Once proper care is taken to compare like with like, no controversy remains. The models do not disagree with the observations; no fundamental revisions to our understanding of how the climate system works are needed.

So was it all a waste of time? Not at all. Even though much of the public discourse surrounding the hiatus was misguided, disingenuous and unfair, it did help to spur some major advances.

An explosion of ocean observations from the Argo float network, for example, solidified understanding that it is the heat content of the entire system, not just air temperature, that matters to measurements of global change. And, post-1998, global heat content kept going up. Whereas the atmosphere seemed to take it easy, the oceans continued to gorge on heat, driven by variations in wind systems. And the seemingly prosaic task of estimating global mean surface temperature from sparse and irregularly spaced observations was shown, in fact, to be as complicated as making great sourdough bread.

In the end, the hiatus controversy led to reinvigorated explorations of many mossy crevasses of climate science. This is not a bad thing, and might not have happened without the public (and political) firestorm. The next time something looks odd in climate science - as it surely will - researchers should once again denounce the inevitable and risible attacks for what they are, while welcoming the opportunity to question their own assumptions, sharpen data sets and revisit collective understanding of the underlying processes. 